International

Medical Society

http://imedicalsociety.org

\title{
Successful Thrombolysis of a Thrombosed Mechanical Aortic Valve Prosthesis Using a Slow Intravenous Tenecteplase Infusion

\section{Abstract}

Prosthetic valve thrombosis is defined as any obstruction of prosthesis by non-infective thrombotic material. It has an estimated incidence of $0.03 \%-4.3 \%$ per year and is reported to occur in $0.5 \%-8 \%$ of the left-sided prosthetic valves and in up to $20 \%$ of tricuspid prosthesis. We describe a successful treatment of a young man presented with a thrombosed prosthetic aortic valve using a slow intravenous infusion of Tenecteplase without any bolus dose in a newly described dose regimen for aortic valve position and with a complete resolution of the thrombus and regaining the full mobility of both valve leaflets within 48 hours.
Amir Mohamed ${ }^{1}$ Aiman Alruwaih", Nael Al-Sarraf1, Medhat Soliman', Mohammad Albanna', Fahad Al- Shammari ${ }^{1}$

1 Department of Cardiac Surgery, Chest Diseases Hospital, Kuwait.

Contact information:

Nael Al-Sarraf.

Address: Al-Jabriah, PO Box 1134, Postal Code 46312, Kuwait.

Tel: 96598882921.

झ" trinityq8@hotmail.com

Keywords

Thrombolysis; Prosthetic Valve Thrombosis; Tissue Plasminogen Activaor.

\section{Case report}

A 31 year old male patient underwent aortic valve replacement with St. Jude $23 \mathrm{~mm}$ mechanical prosthesis valve for severe aortic valve 
Figure 1: Pre-treatment transthoracic ehocardiogram showing decreased mobility of one leaflet with a peak and mean aortic valve gradients of 140 and $90 \mathrm{~mm} \mathrm{Hg}$, respectively.

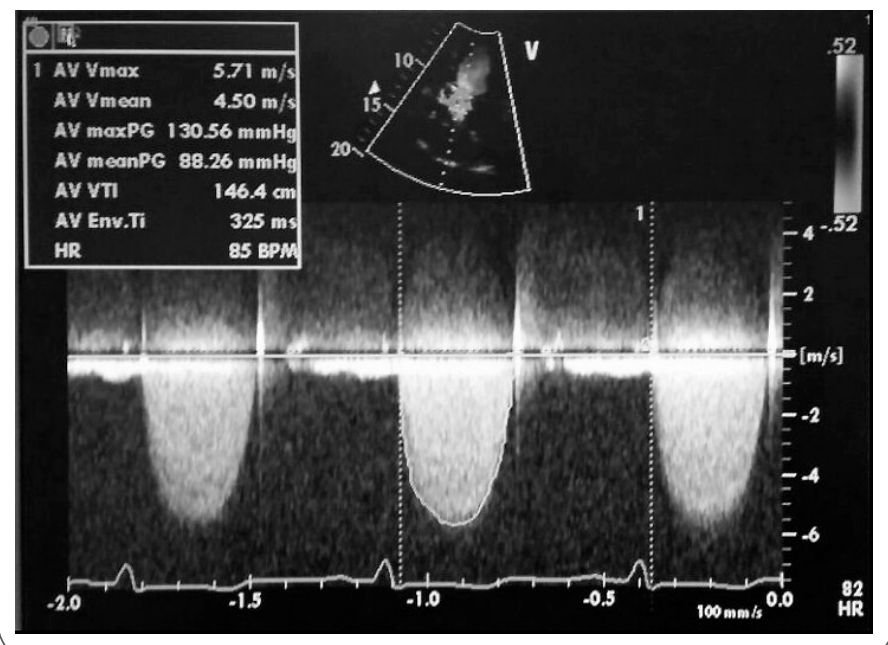

regurgitation and was on oral anticoagulant (warfarin), maintaining a therapeutic International normalized ratio (INR) during follow up. He presented 3 years later with progressively worsening dyspnea of New York Heart Association (NYHA) class II of one month duration. He admitted to not taking his oral anticoagulation for two months prior to presentation. On examination, vital signs were stable with an absent ejection click and a grade 4/6 systolic murmur. Transthoracic ehocardiogram revealed decreased mobility of one leaflet with a peak and mean aortic valve gradients of $140 \mathrm{~mm}$ $\mathrm{Hg}$ and $90 \mathrm{~mm} \mathrm{Hg}$, respectively (Figure 1). Left ventricular function was normal. Fluroscopy showed severely restricted mobility of the leaflet. His INR was normal.

After discussing various options, we elected to treat him with slow intravenous infusion of Tenecteplase (Metalyse, Boehringer Ingelheim) 35 mg diluted in $50 \mathrm{ml}$ normal saline over 24 hours and to be repeated according to the patient's clinical and echocardiographic response. No bolus doses were given. Following thrombolysis, unfractionated heparin infusion and warfarin were commenced until INR
Figure 2: Post-treatment transthoracic echocardiography showing full mobility of aortic valve leaflets with decreased peak and mean gradients to $22 \mathrm{mmHg}$ and $12 \mathrm{mmHg}$, respectively.

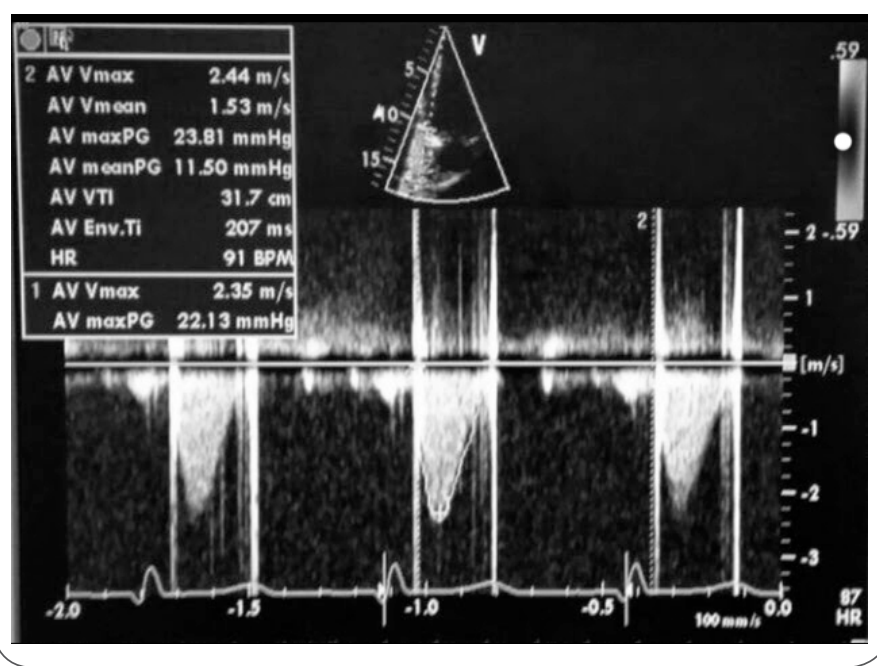

is therapeutic. Small dose Aspirin was added to patient therapy. After thrombolysis, the patient subjectively felt relieved within 6 hours and the prosthetic valve click became sharp, and the systolic murmer decreased to grade $1 / 6$. We continued thrombolysis for further 24 hours. After 48 hours his vitals were stable, the click was well audible and his murmer disappeared. Two dimensional echo showed full mobility of aortic valve leaflets, and aortic valve peak and mean gradients were decreased to $22 \mathrm{mmHg}$ and $12 \mathrm{mmHg}$, respectively (Figure 2). Fluroscopy showed completely mobile prosthetic aortic leaflets. The patient was discharged home with no complication 5 days later.

\section{Discussion}

PVT is defined as any obstruction of prosthesis by non-infective thrombotic material. It has an estimated incidence of $0.03 \%-4.3 \%$ per year [1] and is reported to occur in $0.5 \%-8 \%$ of the leftsided prosthetic valves and in up to $20 \%$ of tricuspid prostheses. The most common cause of PVT is inadequate anticoagulation therapy. [1] Optimal 
management of PVT remains controversial. As per ACC/AHA guidelines 2014, for left-sided PVT, emergency surgery is indicated in patients with NYHA functional class III-IV (class IIa) and fibrinolytic therapy for patients in functional class I-II (class IIb). [2] Lengyel et al considered thrombolysis as the first line of treatment for obstructive PVT, independent of NYHA class and thrombus size, if there are no contraindications. [3] On the other hand, in a recent series of 210 patients reported by Roudant, surgical treatment was associated with significantly better long-term results in terms of recurrence and mortality and a lower incidence of embolic complications, which reached $15 \%$ in the fibrinolysis group (vs. 0.7 $\%$ In the surgery group). [4]

The fibrinolytic agents used for treatment of PVT are streptokinase, urokinase and recombinant tissue plasminogen activator (alteplase). The newer fibrinolytic agent Tenecteplase is a synthetically engineered variant of alteplase designed to have increased fibrin specificity, greater efficacy, increased resistance to plasminogen activator inhibitor1(PAL-1) and a longer half life. It has been used extensively in acute myocardial infarction but there are anecdotal reports of its use in treatment of mitral and aortic PVT. Charokopos et al were the first to publish report of Tenecteplase for aortic PVT. [5] Our patient was symptomatic for 1 month. As Tenecteplase is more fibrin specific, easy to administer and we had previously used it successfully in Mitral valve thrombosis, [6] we felt it was a good choice. In case thrombolysis had failed, re-exploration and redo aortic valve replacement was planned. To our knowledge this is a newly described dose regimen of Tenecteplase in the thrombolysis of a thrombosed prosthetic aortic valve to be given without any intravenous bolus.

PVT can be successfully treated with Tenecteplase. More experience of its use and the rate of its administration might establish its role as the thrombolytic of choice in management of PVT.

\section{Conflict of interest}

None.

\section{Acknowledgement}

None.

\section{Funding}

None.

\section{References}

1. Caceres-Loriga FM, Perez-Lopez H, Santos-Gracia J, et al. Prosthetic heart valve thrombosis: pathogenesis, diagnosis and management. Int J Cardiol 2006; 110: 1-6.

2. Nishimura RA, Otto CM, Bonow RO, et al. 2014 AHA/ACC Guideline for the Management of Patients With Valvular Heart Disease: a report of the American College of Cardiology/ American Heart Association Task Force on Practice Guidelines. Circulation 2014; 129 (23): e521-643.

3. Lengyel M, Horstkotte D, Vo"ller $H$, e al. Working Group Infection, Thrombosis, Embolism and Bleeding of the Society for Heart Valve Disease. Recommendations for the management of prosthetic valve thrombosis. J Heart Valve Dis 2005; 14: 567-575.

4. Roudaut R, Lafitte $S$, Roudaut MF, et al. Management of prosthetic heart valve obstruction: fibrinolysis versus surgery. Early results and long-term follow-up in a single-centre study of 263 cases. Arch Cardiovasc Dis 2009; 102: 269-277.

5. Charokopos N, Antonitsis P, Artemiou P, et al. Acute mechanical prosthetic valve thrombosis after initiating oral anticoagulation therapy. Is bridging anticoagulation with heparin required? Interact Cardiovasc Thorac Surg 2009; 9: 685-687.

6. Al-Sarraf N, Al-Shammari F, Al-Fadhli J, et al. Successful thrombolysis of a thrombosed prosthetic mitral valve using a synthetic tissue plasminogen activator: a case report. J Med Case Reports 2010, 4: 241-244.

\section{Publish in International Archives of Medicine}

International Archives of Medicine is an open access journal publishing articles encompassing all aspects of medical science and clinical practice. IAM is considered a megajournal with independent sections on all areas of medicine. IAM is a really international journal with authors and board members from all around the world. The journal is widely indexed and classified Q1 in category Medicine. 